\title{
ARBITRAGEM JURÍdICA NAS RELAÇÕES TRABALHISTAS NO SETOR SUCROALCOOLEIRO
}

\section{LEGAL ARBITRATION IN LABOR RELATIONS IN BIOFUELS INDUSTRY}

\author{
Juliana Martins Anacleto ${ }^{1}$ \\ Fernando Rodrigues Amorim ${ }^{2}$ \\ Leonardo Augusto Amaral Terra ${ }^{3}$
}

\section{RESUMO}

A presente pesquisa teve como objetivo avaliar como a arbitragem pode contribuir para as relações trabalhistas no setor sucroalcooleiro. Para elaboração da pesquisa foi realizado um estudo de caso em uma usina localizada no interior do Estado de São Paulo. Optou-se por realizar uma pesquisa qualitativa e exploratória. Dessa forma, foram entrevistados os advogados e o gerente da área jurídica de uma usina sucroalcooleira localizada no interior Paulista, que disponibilizaram as informações vitais para a compreensão e posterior comprovação da eficácia da arbitragem. Foi possível concluir que a Justiça Pública não possui capacidade de solucionar todas as questões jurídicas sozinha. Assim, faz-se necessária a adoção de novos métodos para solucionar os conflitos entre as partes. A prática da arbitragem é um método de solucionar os conflitos de maneira mais rápida para proporcionar um desafogamento do Judiciário, principalmente em se tratando dos processos trabalhistas. Os resultados obtidos pela empresa em questão são de extrema importância, visto que através da mensuração dos resultados foi possível compreender que a arbitragem pode contribuir para as relações trabalhistas do setor sucroalcooleiro. Além disso, foi demonstrado que a empresa analisada apresenta grande preocupação com as demandas altamente crescentes de ações trabalhistas.

Palavras-chave: Arbitragem - Negociação - Controvérsias Trabalhistas.

\section{ABSTRACT}

This study aimed to evaluate how the arbitration may contribute in labor relations in the biofuel industry. This research was conducted by a case study in a plant located within 
the State of Sao Paulo. We decided to conduct a qualitative and exploratory research. Thus, we interviewed the lawyers and the legal manager of a sugarcane mill located in São Paulo, which provided the vital information for understanding and subsequent evidence of the effectiveness of the arbitration. As we can notice, the Public Justice does not have the ability to deliberate the legal issues by itself, so it is necessary the adoption of new methods to resolve conflicts between the parties. In this context, it is the practice of an arbitration method that resolves conflicts more quickly and provides the bottlenecking of the judiciary, especially when dealing with labor. The results obtained by the said company are very important, once the measurement of the results would prove that the arbitration may contribute to a better labor relation in the sugar sector; since with the enactment of Law No. 9307/96, the parties have autonomy to choose which method they prefer to resolve conflicts by Public Justice or Arbitration Corte. Furthermore, we proved that the company analyzed is greatly concerned about the growing demands of this area. Finally, we concluded that companies may adopt this method of conflict resolution, because the law in question was created to set new guidelines to the law and, in view of the backlog that the judiciary has, a company needs solutions that are faster and more economic.

Keywords: Arbitration - Negotiation - Labor Disputes.

\section{INTRODUÇÃO}

Atualmente, o sistema judiciário nacional está em crise, a cada 10 processos nas prateleiras apenas três são solucionados no decorrer de um ano (OAB, 2009). Esta morosidade tem levado as pessoas a ficarem insatisfeitas e desconfiadas quando buscam o referido sistema visando solucionar conflitos (SADEK, 2004). Conforme lembra Martins (2002), esta crise institucional também afeta a Justiça do Trabalho. É certo que em todo o país muitas Varas do Trabalho (Juntas de Conciliação e Julgamento) estão abarrotadas de processos trabalhistas, o que implica elevados custos para as organizações e até mesmo para a sociedade.

De acordo com o ex-presidente da Única, Marcos Sawaya Jank (2009), o setor sucroalcooleiro possui duas palavras importantes: mudança e diversidade. A mudança é 
porque o setor está investindo no processo de mecanização da cana-de-açúcar, o que trará uma redução do plantio e da colheita manual. O processo de mecanização já está em andamento em várias usinas da Região Centro/Sul; o que, segundo Moraes (2007), levará a uma diminuição de 134 mil vagas de emprego até as safras de 2020/2021. Alguns lavradores vêm sendo alocados em outras funções como operadores de colheitadeira, motoristas e operadores de máquinas agrícolas de um modo geral. Entretanto, grande parte destes trabalhadores deverá ser dispensada no curto e médio prazo (MORAES, 2007; ÚNICA, 2009).

Uma vez que, no setor sucroalcooleiro muitas são as denúncias referentes às violações de leis trabalhistas (LANGOWSKI, 2007). Muitas das pessoas que deverão ser dispensadas em decorrência da mecanização poderão buscar na justiça a reparação pelos direitos que lhes foram negados. Este cenário tende a provocar o acúmulo de processos trabalhistas, o que é um grande problema para muitas usinas, pois com a sobrecarga das Varas do Trabalho os processos tendem a ser demorados e onerosos.

Este tipo de violação trabalhista ocorre em todas as regiões do país, como exemplo, no ano de 2006 o ministério do Trabalho fiscalizou 74 usinas e todas sofreram autuações. Em 2007, a Procuradoria Regional do Trabalho ajuizou mais de 40 ações civis públicas contra as usinas (MENDONÇA; MELO, 2008). Esse relato nos revela que o setor possui sérios problemas. Diante deste fato, os funcionários e o Ministério do Trabalho a todo tempo recorrem com ações judiciais.

Neste contexto, a busca por meios alternativos para lidar com os conflitos vem crescendo, uma vez que as pessoas procuram por outros métodos de solução de controvérsias. Com a promulgação da Lei $n^{\circ}$ 9.307/96, as pessoas passaram a ter a oportunidade de escolher entre a Justiça Estatal ou a Justiça Privada (Juízo Arbitral) para solucionar os conflitos de maneira mais ágil (LEIRIA; MONTESANO; ALCÂNTARA, 2000). Diante deste fato, a arbitragem aparece como uma possível solução para os problemas encontrados no setor.

“A arbitragem é o procedimento de solução de conflito mediante um órgão ou uma pessoa às quais as partes são submetidas e que proferirá uma decisão. Essa pessoa; suprapartes denomina-se árbitro" (NASCIMENTO, 2004, p.598-9). A possibilidade de utilização da arbitragem na solução de conflitos é clara, pois a Lei no ${ }^{\circ}$ 9307/96 da arbitragem permite a utilização desta prática por qualquer pessoa, assim como a Constituição Federal que, por meio do artigo $144, \S 1^{\circ}$, aponta a possibilidade do uso das 
cortes arbitrais para negociações coletivas, inclusive de âmbito trabalhista (BENTO; SILVA; OLIVEIRA, 2009).

Neste contexto, propõe-se avaliar como a arbitragem pode ser usada para solucionar os litígios trabalhistas, sejam eles coletivos ou individuais, no setor sucroalcooleiro.

\section{CONCEITOS E HISTÓRIA DA ARBITRAGEM}

Segundo Rocha (1998), a arbitragem é um meio de resolver litígios civis voltados para os direitos patrimoniais, onde o árbitro escolhido pelas partes é responsável por tomar a decisão como a Justiça Comum de um órgão do Judiciário. Os Tribunais de Arbitragem ou Câmaras de Arbitragem e Mediação estão presentes em todo o mundo, elas surgiram com o intuito de resolver controvérsias denominadas patrimoniais, como contratos, conflitos trabalhistas, compra e venda de empresas e até processos relacionados à família, como divisão de herança. Eles surgiram pela necessidade de resolver os conflitos de uma forma mais amigável entre pessoas físicas ou jurídicas e têm a finalidade de colaborar, entre outros fatores, para desafogar o Poder Judiciário (TAAB, 2009).

Para Martins (2002, p.82) "na arbitragem, uma terceira pessoa ou órgão, escolhido pelas partes, vem a decidir a controvérsia, impondo a solução aos litigantes. A pessoa designada chama-se árbitro. Sua decisão denomina-se laudo arbitral". A pessoa designada para ser árbitro, pode ser qualquer pessoa capaz, não precisa ser formada em direito, deve possuir apenas os conhecimentos técnicos ou científicos de acordo com o litígio a que foi submetido, ou seja, o árbitro pode ser advogado, engenheiro, administrador, médico, psicólogo etc (FURTADO; BULOS, 1998). Os árbitros devem sempre ser em número ímpar, podendo nomear os seus respectivos suplentes (BRASIL, 1996).

Deste modo, um Tribunal de Arbitragem pode ser composto por um corpo de árbitros: advogados, administradores, contadores, médicos, dentistas, entre outros. De acordo com o processo a serem julgadas, as partes escolherão os árbitros que irão atuar. Dessa forma, os árbitros, especialistas em suas áreas, estarão presentes na resolução dos conflitos (TASP, 2009). 
Segundo Leiria, Montesano e Alcântara (2000) é facultada ao árbitro, de acordo com a Lei $n^{\circ}$ 9.307/96, a conciliação entre as partes, onde o árbitro buscará a melhor negociação, ou seja, ele quem decidirá as controvérsias das partes, buscando o acordo. Ele poderá ouvir testemunhas de ambas as partes, e assim formar seu veredicto. Pode também realizar perícias, ou qualquer outro tipo de prova, mediante um ofício ou requerimento das partes. Para que possa solucionar os conflitos o árbitro deve possuir as seguintes características:

a) Idôneo e imparcial, ou seja, não pode ter interesse no resultado do conflito;

b) Discreto e independente, sem qualquer vínculo com uma das partes, como, por exemplo, ser empregado de uma delas;

c) Capaz perante a lei civil, isto é, ter 21 anos completos e perfeito domínio mental (LEIRIA; MONTESANO; ALCÂNTARA, 2000, p.42).

De acordo com a legislação brasileira, a decisão do árbitro deverá ser cumprida e tal divergência não poderá ser submetida ao judiciário. É como se a palavra do árbitro fosse uma sentença definitiva (BRASIL, 1996). Contudo ainda há divergências quanto a este poder da corte arbitral de se valer como decisão definitiva já que se comprovado que o árbitro foi favorável a uma das partes, ele pode ser processado criminalmente e sua sentença arbitral poderá ser cancelada (BRASIL, 1996).

Segundo Furtado e Bulos (1998), a função do árbitro é facultativa, mas assim que nomeado, o árbitro passa a ser responsável pela resolução do litígio. Caso o árbitro venha a falecer após sua nomeação, estiver impossibilitado de exercer sua função ou seja recusado pelas partes, será nomeado um substituto para desempenhar o seu papel de solucionar os conflitos entre as partes (FURTADO; BULOS, 1998).

Martins (2002, p.91) entende que, "a jurisdição ou tutela é a forma de solucionar conflitos por meio da interveniência do Estado, gerando o processo judicial". A arbitragem poderá ser de direito ou equidade; como direito, o árbitro é comparado à atividade do juiz, neste caso o julgamento é convencional, as partes dispõem um limite na convenção arbitral. No entanto, como equidade, o juiz é o legislador e o juiz ao mesmo tempo, portanto, este domina a lei (ALVIM, 2007). No entanto, o árbitro não poderá impor sua vontade e muito menos antecipar a justiça de direito das partes. A arbitragem busca um equilíbrio, mediando a negociação entre as partes (STRENGER, 1998). Ademais, a arbitragem pode ser espontânea e compulsória. Espontânea seria livre, quando as partes comprometem-se a solucionar litígios futuros pela arbitragem, a 
compulsória seria obrigatória, ela é decorrente da decisão judicial ou da lei (MARTINS, 2002).

No âmbito dos litígios trabalhistas, Martins (2002) argumenta que existem três métodos para solucionar os conflitos: arbitragem, conciliação e mediação. Na arbitragem, as partes elegem uma terceira pessoa ou órgão para decidir a controvérsia, essa pessoa é designada árbitro e possui o poder de um juiz. É uma forma de resolução de conflitos alternativa à Justiça Estatal e que pode contribuir para desafogar a Justiça Pública (LEIRIA; MONTESANO; ALCÂNTARA, 2000).

A conciliação é um método antigo na doutrina jurídica, surgiu para tentar desafogar a Justiça do Trabalho do exuberante número de processos. Essa técnica é vista com bons olhos pelas empresas que podem instituir as comissões de conciliação dentro delas próprias. Seus representantes são empregados e empregadores, e o sindicato é quem institui a comissão. $\mathrm{O}$ conciliador não faz propostas ou mediação, ele apenas intermedia as partes para que cheguem a um acordo. Por fim, a mediação surge quando uma terceira pessoa é chamada para resolver os conflitos entre as partes. $\mathrm{O}$ mediador não precisa ser formado em direito, igual ao árbitro, o que interessa realmente é que esta pessoa venha a mediar o conflito, onde se obtenha várias propostas visando ao desejo das partes (MARTINS, 2002).

\section{CARACTERIZAÇÃO DA PESQUISA}

A pesquisa desenvolvida no presente trabalho foi elaborada mediante um estudo de caso, de caráter exploratório. "O estudo exploratório é designado por alguns autores como pesquisa quase científica ou não científica; é normalmente o passo inicial no processo de uma pesquisa [...]" (CERVO; BERVIAN, 2002, p.69).

O ponto principal de um estudo de caso é a tentativa de esclarecer o motivo pelo qual um conjunto de decisões foram tomadas e implementadas e quais foram os resultados alcançados (YIN, 2001). Assim, o estudo de caso permite uma investigação visando aos eventos da vida real e conta com algumas técnicas utilizadas pelas pesquisas históricas, além de acrescentar duas fontes de evidências que usualmente não são incluídas no repertório de um historiador: observação direta e uma série sistemática de entrevistas (YIN, 2001). 


\subsection{Contextualização do Caso}

A pesquisa se desenvolveu em uma usina sucroalcooleira localizada no interior do Estado de São Paulo. Esta empresa é de grande importância para a economia local e regional e é listada como uma das maiores produtoras de açúcar e álcool do mundo. $\mathrm{O}$ caso foi escolhido pelo porte da instituição e por possuir vários processos trabalhistas similares aos que têm sido relatados no setor sucroalcooleiro.

A empresa explora a cultura da cana-de-açúcar com o objetivo de produzir e comercializar açúcar, álcool e energia e está instalada em uma região de alta relevância no cenário nacional, que se destaca por possuir uma completa infraestrutura em termos de transporte, abastecimento e energia, que favorece o desenvolvimento de importantes polos na indústria do agronegócio.

\subsection{Técnica de Coletas de Dados}

Como instrumento de pesquisa foi utilizada uma entrevista semiestruturada, baseada na aplicação de um questionário com dez questões. Segundo Cervo e Bervian (2002), a entrevista é uma conversa orientada para que se possa chegar a um objetivo específico por meio do interrogatório elaborado pela pesquisa. Neste contexto, foram enviados um questionário ao gestor e cinco questionários destinados aos advogados do departamento jurídico do caso estudado, por meio dos quais foram obtidas as informações. Todos os questionários enviados foram integralmente respondidos.

Depois dos dados coletados, os pesquisadores desenvolveram uma narrativa geral do caso pesquisado e foi selecionado somente o que foi tido como essencial, ou seja, o que possuía ligação com seus objetivos e a construção da pesquisa, conforme proposto por Cauchick (2007).

Esta narrativa contemplou as formas como o gestor e os advogados tratam os processos trabalhistas, bem como, as técnicas utilizadas para a resolução dos conflitos e os benefícios que poderiam ser trazidos pela arbitragem para este processo. Este processo levou em consideração as afirmações de Cervo e Bervian (2002), para quem os fatos explicados e os fenômenos observados são um apanhado de pensamentos onde se 
visa analisar, observar, levantar hipótese e verificar se existem confrontos entre os fatos, colocando as teorias em um contexto mais amplo.

\section{ANÁLISE E DISCUSSÃO DE RESULTADOS}

De acordo com o Tribunal Arbitral de São Paulo e a Câmara de Alçada Brasileira (2009), os conflitos denominados patrimoniais podem atuar nas áreas passíveis de arbitragem e são eles: contratos de compra e venda de empresas, relações trabalhistas e até processos relacionados com herança, nos contratos de compra e venda de transportes, loteamento, comércio internacional, locação residencial e outros.

A empresa estudada evidenciou que possui certa restrição na utilização da arbitragem nas relações trabalhistas do setor sucroalcooleiro. De acordo com o gestor do departamento jurídico, no passado, a empresa adotou formas alternativas de solucionar os conflitos, mas o Judiciário não reconheceu os acordos celebrados e houve resistência dos juízes em reconhecer a autonomia e a validade da transação celebrada sem a interferência do mesmo. $\mathrm{O}$ gestor relatou que em muitos dos casos as pessoas acabaram sendo seduzidas pelos advogados a buscarem o poder Judiciário, onde supostamente poderiam obter melhores resultados.

Esta segurança insegura dos meios particulares pode ser observada também na obra de Cretella Neto (2007), para quem o meio de solução de litígios estatal pode ser aplicado a quaisquer conflitos, isto é, ele é jurisdicional. A pessoa será obrigada a cumprir a decisão judicial, assim que a mesma passar para a fase do trânsito em julgado. Já os meios particulares, como a arbitragem, são aplicados somente em alguns tipos de conflitos, podendo ser aplicados por um árbitro, que nem precisa ser formado em direito ou por uma Câmara de Tribunal Arbitral e pode ser revertido pela justiça caso seja constatada falha processual.

Quando questionados sobre a substituição do Poder Judiciário pela Arbitragem, 66,6\% dos entrevistados disseram que seria possível substituir as demandas judiciais pelas demandas arbitrais, principalmente nos casos onde caberia velocidade na solução dos conflitos. Na arbitragem, as partes elegem uma terceira pessoa ou órgão para decidir a controvérsia; essa pessoa é designada árbitro e possui o poder de um juiz. É uma forma de resolução de conflitos e alternativa à Justiça Estatal e que pode contribuir para 
desafogar a Justiça Pública (LEIRIA; MONTESANO; ALCÂNTARA, 2000). Porém, os entrevistados propuseram que o Estado, por meio de seu legislativo, precisaria definir melhor o Juízo Arbitral para as pequenas demandas, como já acontece com o juizado de pequenas causas, possibilitando que, aos poucos, esta prática fosse estendida para outros ramos do Direito. Segundo o gestor e os advogados, em tese qualquer arbitragem traz benefícios, o que faz deste procedimento um instrumento bastante eficaz na solução dos conflitos.

De acordo com os entrevistados, nas relações empresariais, de um modo geral, a arbitragem reduz os efeitos negativos de uma disputa no Judiciário, onde o resultado final pode levar anos e/ou expor as partes. Estes também argumentam que este tipo de método de solução de litígios também poderia ser muito proveitoso para solucionar litígios de ordem trabalhista, desde que fosse amparado legalmente. Porém, Bento, Silva e Oliveira (2009) defendem que nestes casos, esta não substituirá completamente a atividade jurisdicional estatal, por ainda estar sujeita à revisão dos resultados.

Outro ponto a ressaltar é a formalidade, celeridade e especialidade do árbitro quanto à matéria objeto de julgamento. Os entrevistados destacaram que o procedimento é sigiloso e não necessita de publicidade, evitando assim repercussões negativas para a imagem da empresa que muitas vezes ocorrem com a divulgação dos litígios. Uma vez que os processos não são publicados, acabam deixando as partes mais confortáveis para tratar de suas negociações e até mesmo fazer propostas que não seriam feitas em uma corte estatal, onde poderia abrir precedentes. Os entrevistados também apresentaram o fator custo reduzido do processo como um fator positivo da arbitragem neste tipo de litígio, apesar de a CAESP (2005) ainda apontar que estes ainda podem ser elevados em alguns casos. Posição compartilhada por $16,6 \%$ dos entrevistados que acreditam que a principal desvantagem desta técnica é o alto custo, uma vez, que em alguns casos os valores pagos (honorários) são mais altos do que em um litígio solucionado pelo Poder Judiciário.

A vantagem que teve mais destaque nas entrevistas foi a agilidade na resolução dos conflitos que poderia beneficiar tanto os empregados quanto as usinas. Tal percepção está de acordo com o que foi relatado por Rocha (1998) que explicita que a arbitragem tem decisões mais rápidas do que os tribunais estatais. De acordo com o autor, processos que chegam a demorar 10 anos no Tribunal de Justiça, o Tribunal Arbitral resolve em até 06 meses. $\mathrm{O}$ autor também aponta a simplicidade dos processos 
burocráticos e a especialização do árbitro, de acordo com a natureza da ação, como pontos positivos do uso da arbitragem em relação às cortes estatais. Fatos também observados, com menor intensidade, por todos os entrevistados.

Quando perguntado sobre as desvantagens desta técnica, 50\% dos entrevistados responderam que por ser pouco utilizada e a legislação não ser tão explícita quanto aos seus limites, a arbitragem acaba enfrentando barreiras. Isto ocorre pois se houver grave ofensa â Constituição, como o Tribunal Arbitral não respeitar a ampla defesa ou o contraditório foi parcial, não observando as próprias regras da Lei da Arbitragem, o Judiciário poderá revisar ou anular a decisão do árbitro. Para 33,3\% dos entrevistados, existe, inclusive, uma corrente no Judiciário que não aceita a aplicação da arbitragem nas relações individuais de trabalho, por entender que a empresa, por deter mais poder, pode tanto eliminar, quanto diminuir os direitos dos trabalhadores.

Ao analisar entre as múltiplas possibilidades de solução de litígios, o gestor do jurídico destaca a arbitragem como uma boa técnica para solucionar os conflitos empresariais, internacionais, contratuais e, por fim, causas fundadas em questões técnicas. Em relação aos direitos trabalhistas, o gestor aponta que a melhor solução seria realizar um trabalho preventivo das empresas, visando minimizar as faltas trabalhistas.

Para 66,6\% dos entrevistados, a arbitragem, devidamente regulamentada, seria o melhor método para resolver os conflitos, sejam eles empresariais ou contratuais. Apenas 33,3\% dos entrevistados disseram ser melhor o Poder Judiciário, por possuir maior poder de decisão. Mas vale ressaltar que estes reconhecem que as despesas podem se tornar altas, pela morosidade em solucionar certas controvérsias.

Quando questionado qual a política e procedimento da empresa para resolver as controvérsias do setor, os advogados responderam que hoje é feito um esforço em todas as áreas do Direito para resolução dos conflitos de forma extrajudicial. No entanto, na maioria das vezes, o assunto chega ao Judiciário. O gestor mencionou que mesmo com os benefícios teóricos percebidos na arbitragem, diante da experiência negativa do passado e de um histórico de condenações injustas, a usina tem preferido a solução perante as Varas Trabalhistas, ou seja, pelo Judiciário. Contudo, o mesmo reconhece que se a arbitragem fosse melhor regulamentada este quadro poderia mudar.

Quando perguntados sobre os motivos que os levariam a adotar a arbitragem, $50 \%$ dos entrevistados responderam que os principais motivos seriam: agilidade, flexibilidade, informalidade, sigilo, custos mais baixos em relação à Justiça Comum, 
especialização e cumprimento imediato da sentença arbitral. Dois responderam que os motivos seriam a possibilidade de uma decisão imparcial, proferida por um árbitro altamente especializado no assunto. Por fim, apenas um entrevistado respondeu que não vê motivos para adoção da prática, apesar de ver que ela apresenta vantagens.

Analisando a opinião dos entrevistados sobre se a arbitragem pode proporcionar uma redução nos custos da empresa, o resultado foi que $100 \%$ dos entrevistados responderam que sim, pois as decisões podem ser tomadas mais rapidamente. Esse resultado reflete que a arbitragem é economicamente viável para as empresas, já que proporciona redução de custos quando comparada ao procedimento judicial brasileiro que é moroso, público e pouco eficaz. Porém, é evidente nas entrevistas que a segurança jurídica é um entrave para tal uso, pois ela pode incorrer em custos e desgastes adicionais para a empresa que pode se ver obrigada a pagar duas vezes pelo processo.

Diante deste contexto, todos os entrevistados, quando questionados se a arbitragem seria um método de solução de conflitos que poderia facilitar o dia a dia das empresas, responderam que sim. Entretanto, ressaltaram que no cenário atual isso não se aplicaria para as ações trabalhistas, mas apenas para procedimentos com maior formalidade.

Ao analisar se a empresa pesquisada revela grande preocupação com a demora do Judiciário em resolver os conflitos, obteve-se o seguinte resultado: os advogados ressaltaram que a grande preocupação seria principalmente nos processos trabalhistas, em razão do alto custo de sua manutenção. Contudo, várias ações vêm sendo realizadas pelo Conselho Nacional de Justiça para solucionar o problema, como por exemplo: o estabelecimento de metas para o Judiciário resolver os processos, cursos para os magistrados, o auxílio da arbitragem em alguns casos, dentre outros. Para o gestor do departamento jurídico da empresa pesquisada, a organização se preocupa e muito com a demora do Judiciário em solucionar os conflitos e salienta que essa demora tem um ônus significativo para empresa.

Esta posição contrária ao uso da arbitragem em ações trabalhistas vai de encontro com a opinião de autores como Martins (2002), Bento, Silva e Oliveira (2009) e Morel e Pessanha (2007). Tais argumentam em favor do uso da arbitragem nas questões trabalhistas, apesar de indicarem que esta não substitui a atividade jurisdicional estatal. 
Ao verificar se acreditavam que a arbitragem é utilizada pelas empresas do setor, $33,3 \%$ dos entrevistados responderam que as empresas utilizam contratos prevendo a utilização do procedimento arbitral em suas relações contratuais, trabalhistas, etc. E $66,6 \%$ dos entrevistados responderam que os tribunais arbitrais devem comprovar que são dignos, imparciais e merecedores da credibilidade do setor. Tais entrevistados também destacam que alguns tribunais arbitrais qualificados são caros e talvez seja um dos principais motivos de sua pouca utilização. Por fim, o gestor do departamento jurídico deixou claro que hoje isso é menos frequente pela insegurança jurídica apresentada pela arbitragem. Mas "se as organizações tiverem certeza de que a decisão ou acordo celebrado perante as cortes arbitrais serão respeitados pelo Judiciário, elas tenderão a optar pela arbitragem para solucionar os litígios".

\section{CONSIDERAÇÕES FINAIS}

A arbitragem no Ordenamento Jurídico Brasileiro ganhou destaque e poder com a promulgação da Lei $n^{\circ}$ 9.307/96; através da opinião de vários juristas renomados e estudiosos da matéria, pôde-se verificar que a arbitragem tem potencial para contribuir nas relações trabalhistas do setor sucroalcooleiro, uma vez que a lei traçou novas diretrizes ao Direito e proporcionou à sociedade uma opção adicional de escolha para solucionar os seus conflitos de maneira mais rápida e econômica.

A principal função descrita na literatura para os Tribunais Arbitrais é a solução de controvérsias denominadas patrimoniais, como: contratos, conflitos trabalhistas, compra e venda de empresas, comércio internacional, locação comercial, loteamentos, etc. Esses tribunais são compostos por árbitros altamente especializados, que são escolhidos de acordo com a natureza da ação.

Durante o andamento da pesquisa foi possível identificar uma série de vantagens oferecidas pela arbitragem para a resolução de litígios trabalhistas no setor sucroalcooleiro. Dentre elas se destacaram o tempo e os custos reduzidos nos processos. Contudo, um fato importante apresentado pela análise foi a falta de segurança jurídica que a empresa pesquisada evidenciou. Esta insegurança levou a certa restrição da usina analisada com relação à utilização da arbitragem para solucionar os conflitos trabalhistas. Isso porque, no passado, a empresa tentou adotar essa técnica para 
solucionar os seus conflitos e não obteve êxito, pois os acordos não foram reconhecidos pelo Judiciário.

Porém, no decorrer da pesquisa observou-se que a nova regulamentação trouxe consigo muitos debates; mas hoje, não há como discutir a constitucionalidade da arbitragem na resolução dos conflitos, pois a lei deu ao árbitro o poder de um juiz togado e proporcionou à sentença arbitral os mesmos efeitos da sentença judicial, não cabendo qualquer interferência no mérito da decisão, a não ser que o árbitro tenha descumprido algumas regras, como: nulidade no compromisso, corrupção, possuir relação com as partes, etc. Nesse contexto, não podemos esquecer que o Judiciário não poderá ser substituído pela arbitragem, pois, ambos possuem papéis complementares.

Entretanto, mesmo com a nova redação da lei, a insegurança persiste, até mesmo por conta da resistência de correntes do próprio judiciário em reconhecê-la como método de resolução de litígios. Neste sentido, os resultados deste esforço de pesquisa mostram que, apesar das múltiplas vantagens da técnica, a lei ainda é falha em estabelecer a segurança jurídica necessária para ampla adoção da arbitragem nos litígios trabalhistas. No cenário em pauta, caberia ao governo o papel de propor estímulos de incentivo à arbitragem, através de uma regulamentação detalhada e do convencimento do Judiciário de que a nova Lei da arbitragem surgiu para resolver as controvérsias, os conflitos e/ou litígios de maneira mais ágil e segura.

Diante do que foi analisado sugere-se que as empresas do setor tenham cautela ao adotar a arbitragem para solucionar seus conflitos nos contratos, tais como de energia, fornecimento de cana-de-açúcar, parcerias, prestação de serviços e até mesmo nas questões trabalhistas. Sugere-se como forma de ampliar a segurança que as empresas utilizem cláusulas contratuais ou o compromisso arbitral para se beneficiar, por exemplo, da redução de custos, da agilidade, da flexibilidade e do sigilo das cortes arbitrais.

\section{REFERÊNCIAS.}

ALVIM, J.E. C.. Comentários à Lei de Arbitragem, Lei 9.307, de 23 de Setembro de 1996. Curitiba: Editora Revista e Atualizada, 2007. 
BENTO, V. B.; SILVA, Aurelino Bento; OLIVEIRA, Rafael Lima dos Santos. A Arbitragem no Dissídio Individual Trabalhista. Disponível em: <http://www.jurisway.org.br/v2/dhall.asp?id_dh=973> Acesso em 16 de abril de 2009.

BRASIL. Lei no 9.307, de 23 de setembro de 1996. Dispõe sobre a arbitragem. Diário Oficial da União, Brasília, DF, 24 de setembro de 1996. Seção 1. p. 18.897.

CÂMARA DE ALÇADA ARBITRAL BRASILEIRA - TAAB. Disponível em: <http://www.taab.com.br>. Acesso em 06 de junho de 2009.

CAUCHICK. P. A. M.. Estudo de caso na engenharia de produção: estruturação e recomendações para sua condução. Prod. vol.17 no.1. São Paulo, Jan./Apr. 2007. Acesso em 04 de Agosto de 2009.

CERVO, L. A.; BERVIAN, A. P.. Metodologia Científica Quinta Edição. São Paulo: Pearson Prentice Hall, 2002.

CONSELHO ARBITRAL DO ESTADO DE SÃO PAULO - CAESP. Disponível em: <http://www.caesp.org.br> . Acesso em 11 de junho de 2009.

CRETELla NETO, J.. Comentários à Lei de Arbitragem Brasileira. Rio de Janeiro: Editora Forense, 2007.

FURTADO, P.; BULOS Lammêgo Uadi. Lei da Arbitragem Comentada. São Paulo: Ed. Saraiva, 1998.

GONÇALVES, D. B. Os impactos no meio ambiente. In: WORKSHOP IMPACTOS DA EVOLUÇÃO DO SETOR SUCROALCOOLEIRO, 13., 2008, Campinas. Projeto Programa de Pesquisa em Políticas Públicas. Sorocaba, Unesp, 2008.p. 1 - 10. Disponível em: 〈http://www.apta.sp.gov.br/cana/anexos/position_paper_painel3_daniel.pdf> Acesso em: 24 de maio de 2012. 
LEIRIA, J. S.; MONTESANO, Arlete \& ALCÂNTARA, Sandro Vilela. Manual da Arbitragem como solução do Passivo Trabalhista Empresarial. Porto Alegre: CLT, 2000 .

LANGOWSKI, E. Queima da cana: uma prática usada e abusada. Cianorte: APROMAC, $2007 . \quad$ Disponível em: <http://www.apromac.org.br/QUEIMA\%20DA\%20CANA.pdf>. Acesso em: 16 maio 2012.

MARTINS, Sergio Pinto. Direito Processual do Trabalho. São Paulo: Editora Atlas, 2002.

MENDONÇA, M. L.; MELO, M.. Uma rotina de violações. Disponível em: <http://www.ecodebate.com.br/2008/03/26/direitos-trabalhistas-no-setorsucroalcooleiro-uma-rotina-de-violacoes-artigo-de-maria-luisa-mendonca-e-marlucemelo/>. Acesso em 25 de novembro de 2009.

MORAES, M.A.D.F. O mercado de trabalho da agroindústria canavieira: desafios e oportunidades. Econ. Apl. Vol.11 n.4, Ribeirão Preto, OctlDec. 2007.

MOREL, R. L. M. \& PESSANHA, E. G. da F.. A justiça do Trabalho. Tempo. soc. V19. No2 São Paulo Nov. 2007. Disponível em: $<$ http://www.scielo.br/scielo.php?script=sci_arttext\&pid=S0103$20702007000200003 \& 1 .$. >. Acesso em 25 de maio de 2009.

NASCIMENTO, A. M.. Direito do Trabalho. São Paulo: Editora Saraiva, 1992. ORDEM DOS ADVOGADOS DO BRASIL - OAB. Disponível em: >http://www.oabsp.org.br/palavra_presidente/2008/113>. Acesso em 11 de junho de 2009.

ROCHA, J. de A.. A Lei de Arbitragem (Lei 9.307 de 23 de Setembro de 1996) Uma avaliação Crítica. Brasil: Editora Malheiros, 1998. 
SADEK, M. T. A.. Poder Judiciário: perspectivas de reforma. Opin. Pública, vol.10, n'.1. São Paulo Nov. 2004. Disponível em: $<$ http://www.scielo.br/scielo.php?script=sci_arttext\&pid=SO104$62762004000100002>$. Acesso em 11 de junho de 2009.

STRENGER, Irineu. Arbitragem Comercial Internacional. São Paulo: LTr, 1998.

TRIBUNAL ARBITRAL DE SÃO PAULO - TASP. Disponível em: <http://www.arbitragem.com.br/perguntas.html\#3b>. Acesso em 06 de Abril de 2009.

ÚNICA - União da Indústria de Cana-de-açúcar. Disponível em: <http://www.unica.com.br/opiniao/show.asp?msgCode=\{1160559B-AD54-454E-83A9A0B477196E43\}>. Acesso em 01 de outubro de 2009.

YIN, R. K. Estudo de Caso: Planejamento e Método, 2a Ed., Editora Bookman, 2001.

\footnotetext{
${ }^{1}$ Bacharel em Administração de Empresas pela Faculdade de Educação São Luís.

${ }^{2}$ Bacharel em Administração de Empresa pela Faculdade de Educação São Luís e Mestre em Agroecologia e Desenvolvimento Rural pela UFSCar, doutorando em engenharia agrícola na Universidade Estadual de Campinas.

${ }^{3}$ Bacharel em Administração de Empresas pela Universidade de São Paulo, com MBA Executivo em Gerenciamento de Projetos pela Fundação Getúlio Vargas, Mestrado e Doutorado em Ciências no programa de Administração de Organizações da Universidade de São Paulo.
}

RECEBIDO EM: Abril de 2016

APROVADO EM: Junho de 2016 